IZA DP No. 6100

Anonymous Job Applications

of Fresh Ph.D. Economists

Annabelle Krause

Ulf Rinne

Klaus F. Zimmermann

November 2011 


\title{
Anonymous Job Applications of Fresh Ph.D. Economists
}

\author{
Annabelle Krause
}

$I Z A$

Ulf Rinne

IZA

\author{
Klaus F. Zimmermann \\ IZA and University of Bonn
}

\section{Discussion Paper No. 6100 \\ November 2011}

\author{
IZA \\ P.O. Box 7240 \\ 53072 Bonn \\ Germany \\ Phone: +49-228-3894-0 \\ Fax: +49-228-3894-180 \\ E-mail: iza@iza.org
}

\begin{abstract}
Any opinions expressed here are those of the author(s) and not those of IZA. Research published in this series may include views on policy, but the institute itself takes no institutional policy positions.

The Institute for the Study of Labor (IZA) in Bonn is a local and virtual international research center and a place of communication between science, politics and business. IZA is an independent nonprofit organization supported by Deutsche Post Foundation. The center is associated with the University of Bonn and offers a stimulating research environment through its international network, workshops and conferences, data service, project support, research visits and doctoral program. IZA engages in (i) original and internationally competitive research in all fields of labor economics, (ii) development of policy concepts, and (iii) dissemination of research results and concepts to the interested public.
\end{abstract}

IZA Discussion Papers often represent preliminary work and are circulated to encourage discussion. Citation of such a paper should account for its provisional character. A revised version may be available directly from the author. 


\begin{abstract}

\section{Anonymous Job Applications of Fresh Ph.D. Economists}

Discrimination in recruitment decisions is well documented. Anonymous job applications may reduce discriminatory behavior in hiring. This paper analyzes the potential of this approach in a randomized experiment with fresh Ph.D. economists on the academic job market using data from a European-based economic research institution. If included in the treatment group, characteristics such as name, gender, age, contact details and nationality were removed. Results show that anonymous job applications are in general not associated with a higher or lower probability to receive an invitation for a job interview. However, we find that while female applicants have a higher probability to receive an interview invitation than male applicants with standard applications, this difference disappears with anonymous job applications. We furthermore present evidence that certain professional signals are weighted differently with and without anonymization.
\end{abstract}

JEL Classification: J44, J79, J20

Keywords: $\quad$ Ph.D. economists, annual job market, discrimination, anonymous job applications, randomized experiment

Corresponding author:

Klaus F. Zimmermann

IZA

P.O. Box 7240

53072 Bonn

Germany

E-mail: zimmermann@iza.org

\footnotetext{
* We are grateful to the participants in our experiment who gave permission to use their data. We would furthermore like to thank Marco Caliendo, Martin T. Clemens, Daniela Geppert, Steffen Helbing, Thomas Le Barbanchon, Hilmar Schneider, Ulrike Steins, Julia von Dewitz, and participants at the IZA Workshop on Discrimination and Ethnicity for their comments, help and support. All remaining errors are our own.
} 


\section{Introduction}

Individuals from minority groups face discrimination in several forms and in several markets. Discrimination is for example present within sports, where it influences the referees' decisions in basketball (Price and Wolfers, 2010) or baseball (Parsons et al., 2011), but it is also documented in a wide range of consumer markets such as the market for new cars (e.g., Ayres and Siegelman, 1995) or the housing market (e.g., Ondrich et al., 2003; Bosch et al., 2010). ${ }^{1}$ Nevertheless, the labor market is presumably the most important market in which discrimination is present. The vast body of the literature that aims at identifying, measuring and decomposing the gender wage gap supports this view (see, e.g., Weichselbaumer and Winter-Ebmer, 2005, for a meta-study). But employers' discriminatory behavior in the labor market may not only affect wage setting: it may be already present in the hiring process.

From a theoretical point of view, firms should hire the most productive workersno matter where they are from, what gender they have, or which ethnic group they belong to. Discrimination is a market failure, and it is costly to the firms. For example, Weber and Zulehner (2009) show that firms with strong preferences for discrimination, i.e., a low share of female employees relative to the industry average, have significantly shorter survival rates. On the other hand, there are numerous empirical studies that find a substantial extent of discrimination in the hiring decisions of firms. Examples of such studies that typically use correspondence tests include Bertrand and Mullainathan (2004) for the United States, Carlsson and Rooth (2007) for Sweden, and Kaas and Manger (2011) for Germany.

Discrimination as a market failure provides the basis for policy interventions of various kinds. One intervention, which has recently gained attention and popularity, are anonymous job applications. The intuition is straightforward: removing information about characteristics that employers may discriminate against should reduce or even abandon discrimination in hiring. Discrimination becomes virtually impossible, at least in the first stage of the hiring process which is the decision about the invitation for a job interview. To test whether the desired effects result in practice, several European countries have recently conducted experiments with anonymous job applications (e.g., France, the Netherlands, and Germany). Empirical results are not yet available for the majority of these experiments-with one exception: Aslund and Nordström Skans (2012) analyze an experiment conducted in parts of the local administration in the Swedish city of Gothenburg. Based on a difference-in-differences approach, the authors find that anonymous job applications increase the chances of an interview invitation for both women and applicants of non-Western origin when compared to standard applications. These increased chances in the first stage also translate into a higher job offer arrival rate for women, but not for migrants.

\footnotetext{
${ }^{1}$ See Yinger (1998) for an overview about discrimination in consumer markets.
} 
Our paper adds to the literature on the effects of anonymous job applications and to the literature on the job market for fresh Ph.D. economists. While the data used in the latter literature is fairly old, we use fresh data from an own randomized experiment. ${ }^{2}$ Participants in our experiment are economists who are close to finishing or have recently finished a Ph.D. degree (or equivalent). During the North American annual job market for economists 2010/2011, they applied for a position as a post-doctoral researcher at a European-based economic research institution. Because the treatment was randomly assigned in the experiment, we can rule out any selection into treatment status.

We expect that the introduction of anonymous job applications reduces the extent of discrimination in hiring. Discrimination becomes impossible if the anonymization is effective. Nevertheless, to result in any effects, it is required that discriminatory behavior is present before the introduction of anonymous job applications. One may, however, question that this holds in our specific context. First, discrimination may be lower for high-skilled occupations (including Ph.D. economists). This view is supported, e.g., in Carlsson and Rooth (2007). Second, discrimination may be lower in international labor markets. This argument is related to the previous point and manifests for example in the fact that English is the common language (or lingua franca) in economic research. Third, discrimination may be lower in more competitive labor markets (Weber and Zulehner, 2009), and there is evidence that the particular labor market under study is rather thick (Coles et al., 2010). These three arguments support the view that discrimination in hiring may not be very prevalent in the annual job market for Ph.D. economists. The effects of anonymous job applications may thus be limited in our context.

This paper is organized as follows. Section 2 gives an overview about the annual job market for Ph.D. economists and highlights some important features. Section 3 describes our experimental design and gives an overview about the data. We present and discuss our results in Section 4. Finally, Section 5 concludes.

\section{The Job Market for Ph.D. Economists}

The job search process for economists who are close to finishing or have just recently finished their Ph.D. (or equivalent) is rather exceptionally structured. ${ }^{3}$ Mainly academic institutions, but also government agencies and private firms stand on the demand side. The applicant screening process is an annual procedure. It typically

\footnotetext{
${ }^{2}$ Our study is therefore similar to Goldin and Rouse (2000) who also analyze anonymous job applications in a particular labor market. They find that the introduction of "blind" auditions to select members of symphony orchestras increases the chances of female musicians to be hired.

${ }^{3}$ Cawley (2011) serves as a comprehensive overview and guideline for young economists who plan to participate in the job market.
} 
ranges from September to February, and it is structured in three steps. ${ }^{4}$

The first step takes place in early fall. At this stage, vacancies for Ph.D. economists are posted in the monthly issues of Job Openings for Economists (JOE) and on several other websites (Coles et al., 2010). Candidates send their applications to potential employers, who then decide which applicants they would like to interview. The second stage takes place at the Allied Social Science Association (ASSA) meetings in January, where candidates and employers meet for interviews. The interview dates are set up in advance and interviews take place, e.g., in hotel rooms, in suites, or at tables in large ballrooms. ${ }^{5}$ In a third step, the most convincing candidates are invited to visit the institutions and present their research. These visits are typically scheduled between January and March. Job offers are also communicated during this period. Coles et al. (2010) argue that the number of doctorates awarded from academic institutions and the number of academic and non-academic job vacancies result in a rather thick market. Candidates who receive their Ph.D. from universities other than those based in the United States participate in this job market, too. On the demand side, also institutions which are based outside the United States participate.

The literature on the job market mainly concentrates on the United States. Most studies are concerned with certain determinants of the application process and the supply and demand side in the market, where empirical evidence dates back to the 1980s. These studies analyze the relationship between the applicant's professional characteristics, other socio-demographic factors and interview decisions or job offers. Other studies investigate heterogeneous demand side effects, such as differences in hiring practices between higher-ranked and lower-ranked departments, or they compare the hiring decisions of academic and non-academic employers.

For example, Taube (1987) analyzes the relationship of applicant characteristics on outcomes such as interview invitations, site visits and job offers with survey data from the ASSA meetings in 1987. He finds that males have fewer academic interviews than females, and that the number of publications is significantly positive related with site visits. Moreover, the number of interviews and site visits as well as the number of site visits and job offers are positively related. Similar effects of the number of research papers on the interview decision are documented in Carson and Navarro (1988), who analyze survey data from economic departments in the 1985/1986 job market. They additionally find that the candidate's presentation at the campus visit and the future research agenda are important determinants of a successful job search. In addition, they investigate differences in hiring practices

\footnotetext{
${ }^{4}$ The following description focuses on the primary job market. See Carson and Navarro (1988) for an additional illustration of the preemptive job market and the secondary job market.

${ }^{5}$ About 600 hotel rooms or suites and 150 tables have been booked recently for interviews (Coles et al., 2010).
} 
between the top 20 economic departments and other economic departments. ${ }^{6}$ The use of networks to find candidates and the candidate's research rather than teaching skills are more important for the top departments. At the same time, they require less teaching activities and offer higher base salaries.

Barbezat (1992) uses a database of Ph.D. economists who searched for a job in the 1988/1989 job market. She investigates the importance of the rank of the economic department from the applicant's side and finds that a higher ranking of a potential employer increases the probability that the applicant accepts a job offer from that employer. She furthermore finds that different gender preferences for the time attributed to teaching and research activities, for salary and other benefits, and for collegiality are able to explain that women are more likely to accept a job at liberal arts colleges compared to top-ranked universities. The results concerning the rank of the departments are confirmed by Stock et al. (2000) who use survey data of job candidates and academic departments which recruited economists in the job market in 1995/1996. In addition, they find that candidates who receive a Ph.D. from a higher-ranked department tend to have more interviews and job offers.

List (2000) focuses on interview decisions and compares academic and nonacademic institutions in this regard. He analyzes survey data from first-time job seekers at the ASSA meetings in 1997. He finds that the interview decision of academic departments-as opposed to non-academic employers-is based on research publications of the candidates, a completed Ph.D. from one of the best 19 institutions and reference letters from prestigious economists. Moreover, women receive slightly more academic interview invitations, but less interview invitations from nonacademic employers. Among the socio-demographic characteristics of the applicant, only age plays a statistically significant role for the interview decision, which is negative. List (2001) presents additional results based on similar data. He concludes that gender, age, ethnic background, and citizenship are determinants of the interview decision. Nevertheless, a candidate can influence the probability of receiving an interview invitation by maintaining quality teaching and research portfolios. He furthermore identifies networking as an important factor of success. His estimates suggest that recommendation letters from eminent economists significantly increase the number of interview invitations.

To summarize, the literature generally agrees that the most important determinants of interview and hiring decisions in the job market for high-skilled economists are professional signals of the applicant. These signals include the number of research papers and publications, the time to complete the Ph.D. degree, and the uni-

\footnotetext{
${ }^{6}$ Carson and Navarro (1988) determine the top 20 economic departments through recent rankings. In their case, they include Chicago, Columbia, Cornell, Harvard, Johns Hopkins, MIT, Michigan, Minnesota, NYU, Northwestern, Pennsylvania, Princeton, Rochester, Rutgers, Stanford, UC-Berkeley, UC-Los Angeles, UC-San Diego, Wisconsin, Yale.
} 
versity which the degree is obtained from. However, some studies suggest that the probability of receiving an interview invitation increases (or decreases) depending on gender, age, or ethnic background. This gives rise to the question whether such potentially different treatments are still present when these characteristics are not known to the recruiters, i.e., when anonymous job applications are introduced.

\section{Experimental Design and Sample}

Our experiment took place at a European-based economic research institution during the annual job market 2010/2011. Vacancies for positions as a post-doctoral researcher were posted in two monthly issues of the JOE (October and November 2010). 148 applications were screened in November and December 2010 and 26 candidates were invited for an interview at the ASSA meetings in January 2011. Because of data protection laws, our sample size decreases from 148 applicants to 96 individuals. Participants in the experiment are required to give us permission to use their data, and we therefore electronically asked them to do so. The (positive) response rate of about 65 percent appears reasonable, in particular when considering the time lag of about four months between the application submission and our initial request for permission. ${ }^{7}$ We are moreover not aware of any reason why this procedure should result in a selective sample. For example, our outcome of interest appears not to be related to individual responses. Out of 26 successful candidates who received an invitation for a job interview at the ASSA meetings, six applicants did not give us permission to use their data. Unfortunately, again because of the same data protection laws, we cannot empirically analyze the issue of selective response in more detail. Our final sample consists of 82 individuals when we additionally exclude observations with missing information about age and citizenship.

Importantly, applicants were not aware of the experiment at all. Applications were submitted as in previous years, and no specific requirements were imposed. After the application deadline had expired (November 30, 2010), treatment status was randomly assigned to rule out any selection into treatment group and control group. If included in the treatment group, the applicant's name, contact details, age, nationality, gender and any other indications of the candidate's identity were overwritten with correction fluid. The anonymous job applications were moreover photocopied before handing them to the recruiters, since in most cases the correction fluid did not cover the respective text entirely. The anonymization was done by experienced staff members who were otherwise not involved in the hiring process. This method of anonymizing applications did not prove to be very efficient in past international experiments. However, since recommendation letters are an important

\footnotetext{
${ }^{7}$ We sent out an additional reminder to increase the response rate.
} 
determinant in the application process (List, 2000, 2001) and no serious alternative was available to anonymize continuous text documents, it was decided to carry out the anonymization as described.

The screening process of the applications was conducted as in previous years by the institution's experienced hiring committee. According to the recruiters, a maximum of four to six positions can be filled each year. All members of the hiring committee are male and of European origin. Since the research institution specializes in particular subfields of economics, it can be expected that previous research and publications in these areas are positively valued in the recruitment process. According to the members of the hiring committee, having no previous experience in these subfields may even be a knock-out criterion for otherwise highly qualified candidates. We shed further light on the empirical validity of this statement below.

Table 1 displays descriptive statistics for our treatment and control groups, i.e., the two groups with anonymous and non-anonymous job applications. It becomes apparent that the randomization was indeed successful as any differences between the two groups are not statistically significant. About 20 percent of the sample receive an interview invitation, where the probability for the group with standard applications is slightly higher than for the group with anonymous job applications. About one third of the applicants are female, the average age is around 30 years, and roughly 30 percent have a non-Western background. The candidates have written in total (working papers and publications) between four and five papers. The average number of papers published in A/A+ journals is below one in both groups. About 25 percent receive their Ph.D. degree from one of the top 20 universities. Although this share differs between treatment and control group, the difference is not statistically significant. On average, applicants report that they need about five years to complete their Ph.D. program and less than 20 percent already hold a Ph.D. degree when they apply. Few applicants have work experience outside academia.

The distribution of applicants' characteristics is therefore similar to Barbezat (1992), except that the fraction of women is higher in our sample. This is also the case when we compare our sample to most other samples in the related literature, but it is very likely related to the increasing number of female Ph.D. economists over time-and most other studies use data from more than ten years ago. Another difference to related studies is that we observe a relatively low fraction of applicants from the top 20 departments. But given that most of these departments are based in the United States, and that most applicants who receive their Ph.D. in the United States also apply for a post-doctoral position in this region, it comes as no surprise that applicants from these departments appear more often in North American data.

Finally, Table 1 additionally shows that there is a difference between treatment and control group regarding the applicants' fields of research. Whereas three quarters of the applicants in the sample with standard applications fulfill the requirement 
that their areas of specialization coincide with the subfields of economics in which the institution specializes, this share is about ten percentage points lower in the treatment group. It may therefore be the case that this difference, which is again not statistically significant, explains at least part of the (insignificant) difference in interview invitation rates between treatment and control group.

Table 2 shows that in fact no applicant whose fields of research do not match with the institution's areas of specialization received an invitation for an interview at the ASSA meetings. We therefore exclude 25 observations from our subsequent analysis as having no previous experience in the institution's subfields of specialization actually appears as a knock-out criterion in the screening process. As a result, the raw difference in interview invitation rates reduces to 5 percentage points: 27 percent of the remaining applicants in the group with anonymous job applications received an interview invitation, while this share is 32 percent in the control group.

\section{Results}

Table 3 displays the results of our baseline linear probability model, where the dependent variable equals 1 if an interview invitation is received and 0 otherwise. Socio-demographic characteristics, professional signals and interaction terms between anonymized characteristics and treatment status are added sequentially to the specifications, see columns (1) to (4). The first column displays the raw difference in the invitation probability between applicants with standard applications and those with anonymous job applications. This difference of 5 percentage points is not statistically different from zero, as mentioned above, and it remains statistically insignificant when we include additional control variables. Anonymous job applications themselves therefore do not have an impact on the interview decision.

In columns (2) and (3) of Table 3, we additionally include socio-demographic and professional characteristics. Age has an inversely U-shaped effect on the probability of receiving an interview invitation, but being female or having a non-western background do not significantly influence the recruiters' decision. The number of publications in top journals is positively associated with an interview invitation, although this effect is only marginally significant. Candidates who already hold a $\mathrm{Ph}$.D. degree at the time of the interview have a significantly lower probability to receive an interview invitation. This finding may be related to the timing of entering the market. It is typically the case that applicants enter the market before they have been officially awarded the Ph.D. degree. Therefore, already holding a degree may be interpreted as a negative signal. It likely indicates that the candidate does not 
participate in the market for the first time. ${ }^{8}$ We also find that work experience outside academia has a significantly positive effect on the outcome variable. This can be explained by the orientation of the particular institution because it is not only an academic institution, but also serves as a place of communication between economic research and political practice.

To identify whether anonymous job applications have a different effect on certain groups, we add interaction terms between the treatment status and socio-demographic characteristics in column (4) of Table 3. Interestingly, the coefficient estimate on the interaction term between anonymous job applications and female applicants is significantly negative. On the other hand, the coefficient estimate for female applicants becomes significantly positive. This indicates that a) with standard applications, female applicants are more likely to receive an interview invitation relative to their male counterparts, and b) this relative advantage disappears with anonymous job applications. A story that is consistent with this finding is that female candidates are generally favored in the hiring process at this institution, but such (positive) discrimination is not possible anymore when the applicant's gender is unknown.

Another channel through which differential effects between anonymous and non-anonymous groups may arise are professional signals. One could imagine that these signals might receive a different weight when screening an anonymous application and not knowing the identity of the applicant as compared to the regular screening of a standard application. Hence, Table 4 displays the results of the linear probability model where interaction terms between the different professional characteristics and the treatment status are included. We again sequentially include additional control variables in columns (1) and (2). These results basically mirror our previous findings. In column (3), we include the interaction terms of interest. Our results confirm the hypothesis that certain characteristics of the applicant which are related to his or her education or research portfolio are treated differently under anonymous job applications. This is especially the case for the number of publications in $\mathrm{A} / \mathrm{A}+$ journals. Whereas this professional signal has a negative, but insignificant effect on the invitation probability with standard applications, the effect is significantly positive with anonymous job applications. An explanation is that the recruiters tend to rely more strongly on the "traditional" quality signal of top journal publications when confronted with anonymous job applications.

Overall, these findings have interesting implications for anonymous job applications in general. One may have to take into account not only the potential positive side of concealing certain socio-demographic characteristics, that is to reduce dis-

\footnotetext{
${ }^{8}$ According to Cawley (2011), candidates should enter the market when a) they have a good job market paper completed in fall, and b) they are likely to defend their dissertation in the following spring. He also gives advice to not selectively enter the market and prepare for re-entering the market in the next year, if necessary. In his view, departments are likely to assume that candidates who are on the market for the second time are of low quality.
} 
crimination, but also that other characteristics which are known to the recruiter in any case could be weighted (maybe unconsciously) differently. This may, however, have positive or negative consequences for the applicants.

\section{Conclusions}

We present empirical evidence on the effects of anonymous job applications in a particular labor market, namely the annual job market for Ph.D. economists. We analyze a randomized experiment conducted among applicants for a post-doctoral research position at a European-based economic research institution in 2010/2011. In case of treatment assignment, certain characteristics of the applicant, such as name, gender, age, contact details and nationality, were removed from the applications.

Our empirical analysis shows that anonymous job applications are in general not associated with a higher or lower probability to receive an invitation for a job interview. This finding may appear surprising - given the evidence on discrimination in hiring decisions around the world. However, we identify some characteristics of the particular labor market that may explain why discrimination could be limited. We analyze a high-skilled, international and competitive labor market. Nevertheless, when we investigate the effects separately by gender, we find that while female applicants have a higher probability to receive an interview invitation than male applicants with standard applications, this difference disappears with anonymous job applications. This finding may be related to the fact that female researchers are favored in this particular labor market-or, more specifically, at this particular institutionto promote their chances in research and academia. Evidence shows that women's chances to climb the career ladder are still lower than men's opportunities in this particular labor market (Mixon and Trevino, 2005), but gender discrimination may unfold only at later states (e.g., when promotions are made and/or professorship positions awarded). In any case, the positive discrimination of female economists that we observe with standard applications is not possible with anonymous job applications as the applicants' gender is unknown. Next to these gender differences, our results indicate that certain professional signals of the applicants are weighted differently with and without anonymous job applications. We find evidence that the recruiters tend to rely more strongly on the "traditional" quality signal of top journal publications when they are confronted with anonymous job applications.

The important question to be answered in the long run is whether and whom anonymous job applications serve with their initial purpose, that is to reduce discrimination and to increase the chances of disadvantaged groups in the labor market. Our findings indicate that certain groups may even be hindered in their job chances by hiding their identity. Moreover, other characteristics, which are known 
to the recruiter in any case, may be taken into account differently when screening the anonymous job applications. This effect can result in ambiguous outcomes for the applicants. It is a priori difficult to judge the direction because the interpretation of information is context-specific, and the introduction of anonymous job applications broadly changes the informational context. Whether anonymous job applications are implemented should therefore depend on the characteristics of the particular, narrowly defined labor market. For example, it appears important to take into account the extent of discrimination as well as the characteristics of the hiring process. 


\section{References}

Aslund, O. and O. Nordström Skans (2012). Do Anonymous Job Application Procedures Level the Playing Field? Industrial and Labor Relations Review 65(1).

Ayres, I. and P. Siegelman (1995). Race and Gender Discrimination in Bargaining for a New Car. American Economic Review 85(3), 304-321.

Barbezat, D. A. (1992). The Market for New Ph.D. Economists. Journal of Economic Education 23(3), 262-276.

Bertrand, M. and S. Mullainathan (2004). Are Emily and Greg more Employable than Lakisha and Jamal? A Field Experiment on Labor Market Discrimination. American Economic Review 94(4), 991-1013.

Bosch, M., M. A. Carnero, and L. Farré (2010). Information and Discrimination in the Rental Housing Market: Evidence from a Field Experiment. Regional Science and Urban Economics 40(1), 11-19.

Carlsson, M. and D.-O. Rooth (2007). Evidence of Ethnic Discrimination in the Swedish Labor Market Using Experimental Data. Labour Economics 14(4), 716-729.

Carson, R. and P. Navarro (1988). A Seller's (\& Buyer's) Guide to the Job market for Beginning Academic Economists. Journal of Economic Perspectives 2(2), 137-148.

Cawley, J. (2011). A Guide and Advice for Economists on the U.S. Junior Academic Job Market (2011-2012 Edition). IZA Discussion Paper 5984, Institute for the Study of Labor (IZA), Bonn.

Coles, P., J. Cawley, P. B. Levine, M. Niederle, A. E. Roth, and J. J. Siegfried (2010). The Job Market for New Economists: A Market Design Perspective. Journal of Economic Perspectives 24(4), 187206.

Goldin, C. and C. Rouse (2000). Orchestrating Impartiality: The Impact of "Blind" Auditions on Female Musicians. American Economic Review 90(4), 715-741.

Kaas, L. and C. Manger (2011). Ethnic Discrimination in Germany's Labour Market: A Field Experiment. German Economic Review (forthcoming). DOI: 10.1111/j.1468-0475.2011.00538.x.

List, J. A. (2000). Interview Scheduling Strategies of New Ph.D. Economists. Journal of Economic Education 31(2), 191-201.

List, J. A. (2001). Determinants of Securing Academic Interviews After Tenure Denial: Evidence from a Zero-inflated Poisson Model. Applied Economics 33(11), 1423-1431.

Mixon, F. G. and L. J. Trevino (2005). Is There Gender Discrimination in Named Professorships? An Econometric Analysis of Economics Departments in the US South. Applied Economics 37(8), 849-854.

Ondrich, J., S. Ross, and J. Yinger (2003). Now You See It, Now You Don't: Why Do Real Estate Agents Withhold Available Houses from Black Customers? Review of Economics and Statistics 85(4), 854873.

Parsons, C. A., J. Sulaeman, M. C. Yates, and D. S. Hamermesh (2011). Strike Three: Umpires' Demand for Discrimination. American Economic Review 101(4), 1410-1435.

Price, J. and J. Wolfers (2010). Racial Discrimination Among NBA Referees. Quarterly Journal of Economics 125(4), 1859-1887.

Stock, W. A., R. M. Alston, and M. Milkman (2000). The Academic Labor Market for Economists: 1995-96. Atlantic Economic Journal 28(2), 164-185.

Taube, P. M. (1987). A Cross-Sectional Analysis of the Job market for Economists. Journal of Behavioral Economics 16(4), 33-39.

Weber, A. and C. Zulehner (2009). Competition and Gender Prejudice: Are Discriminatory Employers Doomed to Fail? IZA Discussion Paper 4526, Institute for the Study of Labor (IZA), Bonn.

Weichselbaumer, D. and R. Winter-Ebmer (2005). A Meta-Analysis of the International Gender Wage Gap. Journal of Economic Surveys 19(3), 479-511.

Yinger, J. (1998). Evidence on Discrimination in Consumer Markets. Journal of Economic Perspectives 12(2), 23-40. 
Table 1: Descriptive Statistics I

\begin{tabular}{lccc}
\hline & Non-Anonymous & Anonymous & t-test \\
\hline Interview invitation & 0.244 & 0.171 & 0.811 \\
Female & $(0.435)$ & $(0.381)$ & \\
& 0.341 & 0.366 & -0.228 \\
Non-western origin & $(0.480)$ & $(0.488)$ & \\
& 0.293 & 0.268 & 0.243 \\
Age & $(0.461)$ & $(0.449)$ & \\
& 30.78 & 29.95 & 1.269 \\
Number of papers & $(3.158)$ & $(2.747)$ & \\
& 4.366 & 4.610 & -0.354 \\
Number of publications in A/A+ journals & $(3.352)$ & $(2.862)$ & \\
& 0.073 & 0.195 & -1.266 \\
Ph.D. degree from top 20 university & $(0.461)$ & $(0.511)$ & \\
& 0.171 & 0.293 & -1.306 \\
Years to complete Ph.D. & $(0.381)$ & $(0.461)$ & \\
& 5.000 & 4.707 & 1.080 \\
Holding Ph.D. degree at time of application & $(1.285)$ & $(1.167)$ & \\
& 0.146 & 0.171 & -0.299 \\
Work experience & $(0.358)$ & $(0.381)$ & \\
& 0.122 & 0.049 & 1.181 \\
Research fields match with institution's areas & $(0.331)$ & $(0.218)$ & \\
& 0.756 & 0.634 & 1.195 \\
\hline \# Observations & $(0.068)$ & $(0.076)$ & \\
\hline
\end{tabular}

Source: Own experimental data.

Notes: Standard deviations are in parentheses. Non-western origin is defined as having citizenship from an African, Asian, Latin American, or Eastern European country. A/A+ journals are defined according to the Handelsblatt journal ranking. Top universities are defined as the top 5\% institutions listed by RePEc in July 2011 and include 268 ranks. Top 20 universities include: Harvard, University of Chicago, MIT, LSE, UC-Berkeley, Princeton, Oxford, New York University, Columbia University, Stanford University, Barcelona Graduate School of Economics, Toulouse School of Economics, Boston University, Yale, Northwestern, University of Pennsylvania, University of Michigan, Paris School of Economics, UC-San Diego, and Brown.

Mean difference: *** significant at $1 \% ; * *$ significant at $5 \%$; * significant at $10 \%$.

Table 2: Descriptive Statistics II

\begin{tabular}{lccc}
\hline & \multicolumn{2}{c}{ Research fields match } & with institution's areas of specialization \\
\hline Interview Invitation & No & Yes & \# Observations \\
No & 25 & 40 & 65 \\
Yes & 0 & 17 & 17 \\
\hline \# Observations & 25 & 57 & 82 \\
\hline
\end{tabular}

Source: Own experimental data. 
Table 3: Regression Analysis I

\begin{tabular}{|c|c|c|c|c|}
\hline & (1) & (2) & (3) & (4) \\
\hline Anonymous & $\begin{array}{c}-0.053 \\
(0.123)\end{array}$ & $\begin{array}{c}-0.079 \\
(0.135)\end{array}$ & $\begin{array}{c}-0.038 \\
(0.133)\end{array}$ & $\begin{array}{l}0.262 \\
(0.182)\end{array}$ \\
\hline Female & & $\begin{array}{l}0.095 \\
(0.129)\end{array}$ & $\begin{array}{l}0.143 \\
(0.129)\end{array}$ & $\begin{array}{c}0.473 \\
(0.204)^{* *}\end{array}$ \\
\hline Anonymous $\times$ Female & & & & $\begin{array}{c}-0.811 \\
(0.257)^{* * *}\end{array}$ \\
\hline Non-western origin & & $\begin{array}{l}0.001 \\
(0.143)\end{array}$ & $\begin{array}{c}-0.027 \\
(0.155)\end{array}$ & $\begin{array}{l}0.004 \\
(0.177)\end{array}$ \\
\hline Anonymous $\times$ Non-western origin & & & & $\begin{array}{l}0.329 \\
(0.322)\end{array}$ \\
\hline Age & & $\begin{array}{c}0.393 \\
(0.193)^{* *}\end{array}$ & $\begin{array}{l}0.221 \\
(0.192)\end{array}$ & $\begin{array}{c}0.418 \\
(0.204)^{* *}\end{array}$ \\
\hline Age squared & & $\begin{array}{l}-0.006 \\
(0.003)^{* *}\end{array}$ & $\begin{array}{c}-0.003 \\
(0.003)\end{array}$ & $\begin{array}{l}-0.006 \\
(0.003)^{*}\end{array}$ \\
\hline Number of publications in $\mathrm{A} / \mathrm{A}+$ journals & & & $\begin{array}{l}0.308 \\
(0.220)\end{array}$ & $\begin{array}{c}0.303 \\
(0.159)^{*}\end{array}$ \\
\hline Ph.D. degree from top 20 university & & & $\begin{array}{c}-0.066 \\
(0.153)\end{array}$ & $\begin{array}{c}-0.096 \\
(0.141)\end{array}$ \\
\hline Years to complete Ph.D. & & & $\begin{array}{c}-0.045 \\
(0.049)\end{array}$ & $\begin{array}{l}-0.066 \\
(0.050)\end{array}$ \\
\hline Holding Ph.D. degree at time of application & & & $\begin{array}{l}-0.414 \\
(0.168)^{* *}\end{array}$ & $\begin{array}{c}-0.483 \\
(0.161)^{* * *}\end{array}$ \\
\hline Work experience & & & $\begin{array}{c}0.456 \\
(0.243)^{*}\end{array}$ & $\begin{array}{l}0.318 \\
(0.230)\end{array}$ \\
\hline \# Observations & 57 & 57 & 57 & 57 \\
\hline R Squared & 0.003 & 0.050 & 0.167 & 0.301 \\
\hline
\end{tabular}

Source: Own experimental data.

Notes: Linear probability model. Robust standard errors in parentheses. Dependent variable is equal to 1 if individual was invited for an interview. See Table 1 for additional notes.

*** significant at $1 \%$; ** significant at 5\%; * significant at $10 \%$. 
Table 4: Regression Analysis II

\begin{tabular}{|c|c|c|c|}
\hline & (1) & $(2)$ & (3) \\
\hline Anonymous & $\begin{array}{c}-0.030 \\
(0.121)\end{array}$ & $\begin{array}{c}-0.038 \\
(0.133)\end{array}$ & $\begin{array}{c}-0.310 \\
(0.603)\end{array}$ \\
\hline Female & & $\begin{array}{l}0.143 \\
(0.129)\end{array}$ & $\begin{array}{l}0.172 \\
(0.144)\end{array}$ \\
\hline Non-western origin & & $\begin{array}{c}-0.027 \\
(0.155)\end{array}$ & $\begin{array}{r}-0.075 \\
(0.176)\end{array}$ \\
\hline Age & & $\begin{array}{l}0.221 \\
(0.192)\end{array}$ & $\begin{array}{l}0.430 \\
(0.236)^{*}\end{array}$ \\
\hline Age squared & & $\begin{array}{c}-0.003 \\
(0.003)\end{array}$ & $\begin{array}{l}-0.007 \\
(0.004)^{*}\end{array}$ \\
\hline Number of publications in $\mathrm{A} / \mathrm{A}+$ journals & $\begin{array}{l}0.238 \\
(0.186)\end{array}$ & $\begin{array}{l}0.308 \\
(0.220)\end{array}$ & $\begin{array}{c}-0.135 \\
(0.153)\end{array}$ \\
\hline Anonymous $\times$ Number of publications in $\mathrm{A} / \mathrm{A}+$ journals & & & $\begin{array}{c}0.854 \\
(0.210)^{* * *}\end{array}$ \\
\hline Ph.D. degree from top 20 university & $\begin{array}{c}-0.050 \\
(0.138)\end{array}$ & $\begin{array}{c}-0.066 \\
(0.153)\end{array}$ & $\begin{array}{c}-0.268 \\
(0.219)\end{array}$ \\
\hline Anonymous $\times$ Ph.D. degree from top 20 university & & & $\begin{array}{l}0.172 \\
(0.262)\end{array}$ \\
\hline Years to complete Ph.D. & $\begin{array}{c}-0.033 \\
(0.046)\end{array}$ & $\begin{array}{c}-0.045 \\
(0.049)\end{array}$ & $\begin{array}{c}-0.059 \\
(0.061)\end{array}$ \\
\hline Anonymous $\times$ Years to complete Ph.D. & & & $\begin{array}{l}0.046 \\
(0.113)\end{array}$ \\
\hline Holding Ph.D. degree at time of application & -0.366 & $\begin{array}{l}-0.414 \\
(0.168)^{* *}\end{array}$ & $\begin{array}{c}-0.054 \\
(0.274)\end{array}$ \\
\hline Anonymous $\times$ Holding Ph.D. degree at time of application & & & $\begin{array}{c}-0.444 \\
(0.316)\end{array}$ \\
\hline Work experience & $\begin{array}{c}0.473 \\
(0.249)^{*}\end{array}$ & $\begin{array}{c}0.456 \\
(0.243)^{*}\end{array}$ & $\begin{array}{l}0.407 \\
(0.339)\end{array}$ \\
\hline Anonymous $\times$ Work experience & & & $\begin{array}{l}0.113 \\
(0.459)\end{array}$ \\
\hline $\begin{array}{l}\text { \# Observations } \\
\text { R Squared }\end{array}$ & $\begin{array}{c}57 \\
0.136\end{array}$ & $\begin{array}{c}57 \\
0.167\end{array}$ & $\begin{array}{c}57 \\
0.255\end{array}$ \\
\hline
\end{tabular}

Source: Own experimental data.

Notes: Linear probability model. Robust standard errors in parentheses. Dependent variable is equal to 1 if individual was invited for an interview. See Table 1 for additional notes.

$* * *$ significant at $1 \%$; ** significant at 5\%; * significant at $10 \%$. 